\title{
QUANTIFICATION OF THE EFFECTS OF KETOSIS ON REPRODUCTION IN DAIRY COWS BY META-ANALYSIS
}

\author{
C. Fourichon, H. Seegers and X. Malher
}

Unit of Animal Health Management, Veterinary School \& INRA, BP 40706, 44307 Nantes Cedex 3, France

Effects of ketosis on reproduction were reviewed and summarised according to meta-analysis methods. Thirteen peer-reviewed papers in English based on data issued after 1960 from dairy intensive regions were selected. Summary estimates and $95 \%$ confidence intervals were calculated according to general variance-based methods for meta-analysis. Possible reasons for heterogeneity of the results were investigated among origin of the data and study design. Clinical ketosis and ketosis diagnosed by a test for ketone bodies in milk or blood were considered separately.

Effects varied widely between studies. Summary estimates $[95 \% \mathrm{CI}]$ of effects of clinical ketosis were $2.5[1.0,4.1]$ more days to first service, 3.8 less \% conception at first service, $5.9[3.0,8.8]$ more days to conception, $0.13[0.06,0.19]$ more services per conception, and a hazard ratio of $0.87[0.82$, $0.91]$ to conceive between 56 and 120 days postpartum.

Different thresholds were used in studies detecting ketotic cows by a test. Results were discrepant and studies with the lowest thresholds concluded in the highest effects. Clinical cases are more likely to be detected and treatment probably contributes to limit their effect.

In Holstein cows from US or Canada herds, no significant effect was evidenced. In Swedish Red and White and Swedish Friesian cows, effects were small or non significant. The highest effects were evidenced in Finncattle, Finnish Friesian or Finnish Ayrshire cows. Results suggest that under current farming conditions, effects of ketosis on reproduction are on average limited, but show large variations in different production systems.

\section{EFFECTS OF POLYUNSATURATED w-3 FATTY ACIDS ON SHORT TERM REGULATION OF HEPATIC FAT METABOLISM IN LIVER TISSUE FROM DAIRY COWS}

\author{
Jens Bech Andersen ${ }^{1}$, Anna-Sofie Hansen ${ }^{1}$, Noah B. Litherland ${ }^{2}$, Liselotte R. Norup ${ }^{1}$, \\ Mette Olaf Nielsen ${ }^{3}$, James K. Drackley ${ }^{2}$ and Klaus Lønne Ingvartsen ${ }^{1}$
}

${ }^{1}$ Department of Animal Health and Welfare, Research Centre Foulum, P. O. Box 50, DK-8830 Tjele. ${ }^{2}$ Department of Animal Sciences, University of Illinois, Urbana $61801,{ }^{3}$ Royal Veterinary and Agricultural University, Department of Anatomy and Physiology, DK-1870 Frederiksberg C

\section{Introduction}

Hepatic lipidosis is a common disorder in dairy cows in the peri-parturient period, and the negative aspects have been well documented (1). The accumulation of fat in the liver is caused by an increased influx of nonesterified fatty acids (NEFA) to the liver in situations of high mobilization. This indicates that an increased amount of long chain fatty acids (LCFA) is directed towards triglyceride (TG) synthesis rather than towards oxidation. In rat liver tissue it has been found that $\mathrm{w}-3$ polyunsaturated 
fatty acids ( $\omega$-3 PUFA) like eicosapentaenoic acid (EPA; (20:5, $\omega-3)$ ) and a-linolenic acid (LIN; $18: 3, \omega-3)$ are capable of depressing the rate of TG synthesis and stimulating rate of LCFA oxidation $(2,3)$. The aim of the present study was to investigate if w-3 PUFA in the bovine liver could act to prevent hepatic TG accumulation within a few hours of acutely increased mobilization. The aim was addressed by examining the short-term effect of EPA and LIN on the capacity for in vitro oxidation, ketogenesis, and TG formation from palmitate in liver tissue from lactating dairy cows.

\title{
Material and methods
}

The liver tissue was obtained from 3 mid-lactating dairy cows fed a standard TMR. Fresh tissue was prepared by slicing cored liver on a motorized tissue slicer. The slices were incubated for $3 \mathrm{~h}$ in basal media containing $1.0 \mathrm{mM}$ palmitate and one of either EPA, LIN or palmitate (control) in a final concentration of $1.2 \mathrm{mM}$. The capacity for oxidation $\left({ }^{14} \mathrm{CO} 2\right)$, ketogenesis $\left({ }^{14} \mathrm{C}\right.$ acid-soluble product (ASP)), and TG synthesis $\left({ }^{14} \mathrm{C} \mathrm{TG}\right)$ of $\left[1-{ }^{14} \mathrm{C}\right]$ palmitate in the tissue incubation system was measured.

\section{Results and discussion}

The capacity for TG synthesis was not affected by the $2 \omega-3$ PUFA's. Compared to incubation with palmitate alone, the complete oxidation of palmitate to $\mathrm{CO}_{2}$ was decreased by $17 \%$ in the presence of $\omega-3$ PUFA, but this was only significant for LIN ( $\mathrm{P}=0.006)$. The ASP formation was depressed by $30 \%$ in the presence of LIN ( $\mathrm{P}=0.01)$, but was unaffected by EPA. In conclusion, we were not able to demonstrate any positive short-term effects of $\omega-3$ PUFA on hepatic LCFA metabolism in dairy cows with respect to prevention of hepatic lipidosis. There is need for further experiments to examine any potential longer time effects of $\omega-3$ PUFA on hepatic fat metabolism in dairy cows, mediated by increased or decreased enzyme abundance.

1. Drackley, J.K, J. Dairy Sci., 82 (1999), 2259-73;

2 Berge, R. K. et al.. Biochem. Journal, 343 (1999), 191-197; (3): Kabir, Y. and Ide, T. Biochemica et Biophysica, 1304 (1996), 105-119.

\section{EFFECT OF TRANSITION FROM CONVENTIONAL MILKING TO ROBOTIC MILKING ON TEAT SKIN AND TEAT END CONDITION}

\author{
${ }^{1,2}$ S.De Vliegher, ${ }^{1,2}$ H.Laevens, ${ }^{1}$ G.Opsomer, 3 K.Fischer, ${ }^{4}$ J.Christiaens, ${ }^{5}$ I.Laquiere, \\ ${ }^{6}$ T.Hemling, ${ }^{6}$ M. McKinzie, ${ }^{1}$ A.de Kruif
}

\footnotetext{
${ }^{1}$ Department of Reproduction, Obstetrics and Herd Health, ${ }^{2}$ Veterinary Epidemiology Unit, Faculty of Veterinary Medicine, Ghent University, 9820 Merelbeke, Belgium - ${ }^{3}$ Department of Applied Mathematics and Informatics, Faculty of Science, Ghent University, 9000 Ghent, Belgium - ${ }^{4}$ Biocentrum Agri-Vet, Ghent University, 9820 Melle, Belgium - ${ }^{5}$ DeLaval International, Business Unit Hygiene, 9031 Drongen, Belgium ${ }^{6}$ DeLaval International, Business Unit Hygiene, Kansas City, MO 64105,USA
}

The introduction of an automated milking system into a dairy herd could possibly affect teat skin and teat end condition. Under a voluntary milking system (VMS ${ }^{\mathrm{TM}}$, DeLaval) the cows will be milked 
more frequently than under a conventional milking system. The effect of transition from conventional milking to robotic milking was examined in a clinical trial while using a high emollient iodine teat dip (Proactive Plus ${ }^{\mathrm{TM}}$, DeLaval).

Forty lactating cows and heifers from a high yielding dairy herd were randomly allocated to a control and VMS group, each group containing 9 heifers and 11 multiparous cows. In the VMS group, robotic milking was initiated during the study period, while in the control group conventional milking was continued during the whole study period. Teat skin condition (TSC) and teat end condition (TEC) were evaluated weekly on quarter level for all 40 cows from 5 weeks before until 8 weeks after initiation of automated milking, using a classification system going from 1 (smooth teat skin and end sphincter) to 5 (severely damaged teat skin and end). The same teat dip was used on all teats of all cows during the whole study period. Statistical analysis was performed using the Generalized Estimating Equations (GEE) methodology for longitudinal data, leaving the correlation matrix unstructured (S-Plus $2000^{\circledR}$ for Windows).

In total, 2045 teat skin scores and 2034 teat end scores were recorded during the study period. Results of mean teat skin scores (MTSS) and mean teat end scores (MTES) per group ( \pm SEM), prior and after initiation of robotic milking, and mean milking frequencies (MMF) ( \pm SEM) per day after initiation of robotic milking for the VMS group, are given in Table 1:

\begin{tabular}{|c|c|c|c|c|c|c|}
\hline & & MTSS & & MTES & & MMF \\
\hline $\begin{array}{l}\text { Group } \\
\text { After }\end{array}$ & Lactation number & Prior & After & & Prior & After \\
\hline Control & Heifers & $1,17 \pm 0,03$ & $1,37 \pm 0,03$ & $1,06 \pm 0,02$ & $1,14 \pm 0,02$ & l \\
\hline Control & Multiparous cows & $1,21 \pm 0,03$ & $1,32 \pm 0,02$ & $1,38 \pm 0,04$ & $1,61 \pm 0,04$ & 1 \\
\hline VMS & Heifers & $1,20 \pm 0,03$ & $1,24 \pm 0,02$ & $1,10 \pm 0,03$ & $1,40 \pm 0,03$ & $2,5 \pm 0,1$ \\
\hline VMS & Multiparous cows & $1,18 \pm 0,03$ & $1,21 \pm 0,02$ & $1,38 \pm 0,05$ & $1,35 \pm 0,03$ & $2,6 \pm 0,1$ \\
\hline
\end{tabular}

When considering TSC, the VMS group showed consistent scores from before and during milking with the VMS ${ }^{\mathrm{TM}}$. The control group did not perform as well as the VMS group $(\mathrm{P}<0.001)$, but cow handling may have been a contributing factor. Rear quarters had a better TSC than front quarters $(\mathrm{P}<0.001)$. When only considering the animals in the VMS group, more frequent milking resulted in a higher score $(\mathrm{P}<0.001)$. It was concluded that the transition to robotic milking did not influence TSC much, as teat skin scores in the VMS group were stable during the study period. Any potential effect of more frequent milking on the TSC may have been mitigated using the teat dip.

For TEC, the results were mixed. The multiparous cows in the VMS group performed better than their control group $(\mathrm{P}<0.001)$. The heifers in the VMS group showed a increased score compared to their controls $(\mathrm{P}<0.001)$, but the mean score was still very good. When only considering the animals in the VMS group, more frequent milking resulted in a higher teat end score $(\mathrm{P}<0.001)$. Transition from conventional to automated milking influenced TEC of the VMS heifers negatively, when compared with the control heifers. The opposite was true for the VMS multiparous cows, as their TEC was better than the control multiparous cows. 